\title{
O CONCEITO DE DIREITO E A PROPOSIÇÃO JURÍDICA: LIÇÕES A PARTIR DO CAPÍTULO III DE TEORIA PURA DO DIREITO (1934)
}

\section{Leandro José de Souza Martins *}

Resumo: Este artigo apresenta as linhas gerais do Capítulo III de "Teoria Pura do Direito", de Hans Kelsen, conforme a Primeira Edição, escrita em 1934. Para tanto, demonstra como Kelsen, desde o título do capítulo, fundamenta-se em uma tese cuja centralidade é a conceituação do direito como ordem de coação pela proposição jurídica. A teoria pura do direito representa o direito positivo por meio do "dever ser", bem como um aparato de coação, centralizado na norma jurídica. A norma jurídica se expressa como proposição jurídica que, sob a condição da conduta oposta, um ato de coação deve ocorrer como consequência.

Palavras-chave: Teoria Pura; Positivismo; Proposição Jurídica; Norma; Coação.

\section{THE CONCEPT OF LAW AND THE LEGAL PROPOSITION: LESSONS FROM CHAPTER III OF PURE THEORY OF LAW (1934)}

\begin{abstract}
This article presents the guidelines of Chapter III of "Pure Theory of Law", by Hans Kelsen according to the First Edition, it was written in 1934. For this end, this paper wants to demonstrate how Kelsen, from the title of the chapter, based on the elaboration of a thesis whose centrality is the conceptualization of law as an order of coercion by the legal proposition. The pure theory of law represents positive law through "Ought", as well as a coercive apparatus, on the legal norm. The legal norm is expressed as a legal proposition that expresses that, under the condition of the opposite conduct, an act coercive occurs as a consequence.
\end{abstract}

Keywords: Pure Theory; Positive Law; Legal Proposition; Norm.

\section{Introdução}

Em língua portuguesa, especificamente em edições acessíveis ao público brasileiro, a Teoria Pura do Direito de Hans Kelsen foi traduzida a partir da segunda edição alemã, originalmente publicada em 1960. Como conhecido, esta edição traz o amadurecimento de toda intelecção teórica feita por Kelsen em torno de uma teoria do direito. Grande parte dos comentários e estudos são feitos mediante a leitura dessa segunda edição.

\footnotetext{
* Mestre em Filosofia pela Universidade Federal de Ouro Preto (UFOP/Filosofia da Arte e Estética); doutorando em Teoria do Direito e Justiça pelo Programa de Pós-Graduação em Direito da PUC-Minas; especialista em Docência pelo Instituto Federal Minas Gerais e em Filosofia pela UFOP; bacharel em Direito pela Faculdade de Direto de Conselheiro Lafaiete. Professor EBTT de Filosofia, Sociologia e Introdução ao Direito no Instituto Federal de Minas Gerais (IFMG), Campus Ouro Branco. Endereço eletrônico: leandro.martins@ifmg.edu.br. Lattes: http://lattes.cnpq.br/8239895889023815. O presente trabalho foi realizado com apoio da Coordenação de Aperfeiçoamento de Pessoal de Nível Superior - Brasil (CAPES) - Código de Financiamento 001.
}

Teorias do Direito e Realismo Jurídico | e-ISSN: 2525-9601| Encontro Virtual | v. 7 | n. 1 | 
Para este artigo, entretanto, escolheu-se como texto-base a primeira edição da Teoria Pura do Direito, publicada originalmente em 1934. Tal edição está recém traduzida no Brasil pelo Professor Alexandre Travessoni Gomes Trivisonno. Justifica-se o uso desta edição tanto o fato de apresentar ao leitor essa novel tradução, quanto a intenção de demonstrar como Kelsen trabalha já na década dos anos 1930 as formulações sobre o conceito de direito e sobre a proposição jurídica, desenvolvendo-as, como será visto, sob forte influência do neokantismo.

De fato, na primeira edição, já é evidente o esforço de Kelsen de defender uma ciência do direito pura, isto é, sem interferências de outros campos do conhecimento que não agem na precisa delimitação do direito, como a religião, a política e a moral. Além disso, a obra já oferece aprofundamentos sobre a estrutura escalonada da norma (capítulo V), o processo da interpretação (VI) e, antes de tudo, a apresentação do direito como ordem normativa coativa, fora dos dualismos tradicionais e voltado para o direito como é (III e IV).

Com tal percurso e temáticas, Kelsen elabora sua teoria pura ${ }^{2}$ enquanto um verdadeiro princípio metodológico, procurando responder sobre o que é como é o direito (KELSEN, 2021, p. 13), excluindo quaisquer considerações, valorativas e sociopolíticas. Conforme expressa no capítulo inicial da Teoria Pura do Direito, propõe-se a "assegurar um conhecimento dirigido apenas ao direito", excluindo desse conhecimento "aqueles determinados objetos que não pertencem precisamente ao direito" (KELSEN, 2021, p. 13). Compreender o fenômeno jurídico significava desvinculá-lo de qualquer relação necessária com a moral ou de uma pretensão essencial de promoção da justiça, cujo conteúdo era considerado por Kelsen de forma nenhuma racional ou cientificamente apreensível. A justiça, para ele, não passava de um ideal irracional.

Particularmente, este artigo tem como objeto apresentar, sucinta e esquematicamente, as linhas gerais do capítulo III da primeira edição de Teoria Pura do Direito, no qual Kelsen expõe dois elementos centrais de sua teoria: o próprio conceito de direito e a doutrina da proposição jurídica. Estes conceitos serão articulados, desenvolvidos e se ligarão a outros fundamentais para a teoria pura. São verdadeiros pressupostos para compreender a leitura positivista do Direito em Kelsen, bem como para a acepção mais coerente em relação à visão kelseniana de Direito enquanto norma/ordenamento.

\footnotetext{
${ }^{2}$ Para fins de diferenciação, entende-se pela expressão "teoria pura" (escrita em minúsculas), como o conjunto integral da obra de Kelsen. Quando se tratar do livro específico (de qualquer edição), a redação será pela expressão completa "Teoria Pura do Direito" (redigida em maiúsculas).
} 
Especificamente, o artigo não segue literalmente a ordem estabelecida por Kelsen em seu texto, mas reorganiza as ideias do jurista vienense em três grandes blocos, a saber: a) a conceituação de Direito, afastada da concepção jusnaturalista e centrada no Direito Positivo; b) a Doutrina da Proposição Jurídica e do Dever Ser e, por fim, c) a coação como especificidade da proposição jurídica, ao lado da Doutrina da Estrutura da Norma. A justificativa para tal reorganização baseia-se na tentativa de demonstrar o quanto o capítulo III se fundamenta na elaboração de uma tese cuja centralidade é a conceituação do direito como ordem de coação pela proposição jurídica.

O método utilizado para a realização do trabalho foi descritivo-analítico, com releitura das categorias fundamentais para o desenvolvimento do tema presentes no capítulo III da obra de Kelsen. Por isso, não há referências a outros conceitos importantíssimos para a doutrina kelseniana desenvolvidos em outros capítulos, o que implica um caráter incipiente e estritamente delimitado para o que se desenvolve neste artigo. Ressalte-se que os procedimentos técnicos utilizados na pesquisa para coleta de dados foram tanto o estudo do texto da primeira edição da Teoria Pura do Direito, quanto a pesquisa bibliográfica em artigos referentes à temática.

\section{O contexto da primeira edição da Teoria Pura do Direito e influências}

\subsection{Uma breve notícia relativa à periodização da obra}

Importa ressaltar, inicialmente, que a primeira edição da Teoria Pura do Direito (1934), foi redigida em período em que Kelsen foi fortemente marcado pela filosofia transcendental kantiana, nos moldes do neokantismo, informação aferida tendo em vista os muitos trabalhos de periodização da obra de Kelsen. A periodização da obra de Kelsen é uma linha de pesquisa importante, sobretudo por causa de três elementos: o primeiro, é a constatação do longo período de tempo que a obra de Kelsen possui.

De fato, Kelsen evolui seu pensamento especialmente entre os anos 1911 e 1960 e seguintes. Em consequência, e, aqui, um segundo argumento, neste longo período de redação, Kelsen escreve coisas relevantes e integradoras para sua teoria, seja complementando-a ou até mesmo aperfeiçoando-a. Por fim, a importância da periodização ajuda a esclarecer e relevar a 
influência (em maior ou menor escala) do pensamento crítico de Immanuel Kant e do Neokantismo na obra de Kelsen ${ }^{3}$.

Em termos mais simples, as tratativas em torno de apresentar uma periodização do pensamento e Kelsen não só identificaram temporal e cronologicamente os mais de quatrocentos trabalhos elaborados por Kelsen ao longo de tantas décadas, como também testemunham uma evolução conceitual ao longo do tempo da obra kelseniana.

Destaca-se, dentre as periodizações, a proposta por Stanley Paulson ${ }^{4}$, em seu texto de 1998, quando elabora uma crítica à periodização apresentada por Carsten Heidemann, em 1996. Paulson apresenta como uma periodização da obra de Kelsen a partir da proposição de três fases, a saber: $1^{a}$ fase - "Construtivista" (1911-1913); 2 2a fase - "Clássica", introduzida por um Período de Transição (1913-1922) e subdividida em "Neokantiana" (1922 a 1935) e "Híbrida" (1935 a 1960). Por fim $3^{\text {a }}$ fase - "Cética" (1960 em diante).

O período entre 1922 a 1935 é fortemente marcado pelo neokantismo. Trata-se, segundo Paulson, de um longo período kantiano, um período denominado "clássico", no qual Kelsen se esforçará para estabelecer e fundamentar, seja no argumento transcendental kantiano ou em um método neokantiano, um suporte para suas construções teóricas em relação ao direito.

Paulson tem outra maneira de periodizar a obra de Kelsen. Nesta forma, mais antiga (1990), Paulson distingue quatro fases: a primeira (1911-1921), denominada "construtivismo crítico"; a segunda, de neokantiana forte ((1920 a 1930) e a terceira, neokantiana fraca (fins de 1930 até 1960). Uma quarta fase representaria ruptura com as doutrinas kantianas a partir de 1960. Não obstante, em ambas as proposições, Paulson demonstra a importância e influência do pensamento neokantiano quando Kelsen escreve a Teoria Pura do Direito em 1934. (cf. PAULSON, in: GIANFORMAGGIO, 1990, p. 11-47) ${ }^{5}$.

Portanto, o contexto da primeira edição da Teoria Pura do Direito é herdeiro de influências filosóficas e teóricas da filosofia transcendental de Kant na Crítica da Razão Pura e pela releitura da metodologia crítica em círculos reconhecidos coletivamente por

\footnotetext{
${ }^{3}$ Sobre períodos do pensamento de Hans Kelsen, importante conferir os trabalhos de Mario Losano (1966) Wolfgang Schild (1971) e Eugenio Bulygin (1990), todos devidamente referenciados em TRIVISONNO, 2021, p. XXVIII a XX.

${ }^{4}$ Cf. PAULSON, Stanley L. Four Phases in Kelsen's Pure Theory of Law? in: Oxford Journal of Legal Studies, n 18, v. 1, p. 153-166, 1998; esse texto está traduzido e seguido de Pós-Escrito Inédito em OLIVEIRA; TRIVISONNO, 2013, p. 3-37).

${ }_{5}^{5}$ Aprofundamentos sobre a temática: LOSANO, Mario G, Saggio Introdutivo in: KELSEN, 1966, XII-LVII; e TRIVISONNO, Alexandre Travessoni Gomes, Estudo Introdutório, in: KELSEN, 2021, p. XXVI-LXXIV.
} 
"Neokantismo". De fato, a Teoria Pura do Direito continua na esteira da negação da metafísica, não incorrendo nos problemas das teorias jusnaturalistas, assumindo certa postura relativista. Conforme será visto, Kelsen rejeita toda possibilidade de um Direito Natural e de seus desdobramentos em sua teoria, de modo que a chave de leitura de toda concepção o kelseniana de direito como norma provenha de um argumento kantiano (Cf. CONSANI, 2016, p. 137).

\subsection{O neokantismo em Kelsen}

Na Introdução à obra "O Problema da Justiça" (KELSEN, 1998), Losano argumenta que os pressupostos neokantianos em Kelsen estão atrelados, primeiramente, na "pureza metodológica" da doutrina. Ora, a teoria pura é uma teoria que "procura responder à questão 'o que é como é o direito"'. Procura, portanto, delimitar a especificidade da ciência do direito, subtraindo tudo que dele seria considerado não normativo. Citando expressa e literalmente Ota Weinberg, Losano explica que

(...) a concepção geral que Hans Kelsen tem da ciência e a sua determinação da ciência jurídica são responsáveis pela ideia de que cada ciência deve corresponder um todo metodologicamente unitário e, portanto, segundo sua terminologia neokantiana, de que o objeto da ciência é determinado antes de mais nada pelo seu método, ou seja, por seu modo de observar e compreender as coisas (LOSANO, Introdução, in: KELSEN, 1998, p. XIII).

A delimitação do conhecimento científico recebeu, com Kant, um tratamento especial. De fato, Kant desenvolveu sua tese a ponto de estabelecer, por meio da crítica da razão, um verdadeiro tribunal, a fim de delimitar seu alcance e possibilidades. A metodologia crítica abordada por Kant, e que torna a Crítica da Razão Pura um dos marcos da Filosofia, apresenta, dentre todos os desdobramentos da "revolução copernicana kantiana", a marcação de uma ideia: o modo como o sujeito conhece constitui, neste modo, o próprio objeto estudado.

Com efeito, Kant, na Crítica da Razão Pura [KrV B 25 (KANT, 1989, p. 53; 92)], define transcendental como "todo o conhecimento que em geral se ocupa menos dos objectos, que do nosso modo de os conhecer, na medida em que este deve ser possível a priori”. Kant ( $K r V$ B 81) volta ao conceito de transcendental em outras passagens, destacando-se duas: "a possibilidade ou o uso a priori do conhecimento"; "não todo conhecimento a priori, mas 
somente àquele que pelo qual conhecemos que e como certas representações (intuições ou conceitos) são aplicadas ou possíveis simplesmente a priori”. Joaquim Carlos Salgado reescreve a definição kantiana, afirmando que transcendental é

\begin{abstract}
todo conhecimento pelo qual nós conhecemos serem certas representações (intuições ou conceitos) aplicadas a priori ou pelo qual conhecemos como são possíveis a priori. Daí que a priori não é exatamente transcendental. Transcendental quer dizer possibilidade, ou o uso a priori do conhecimento. O espaço, por exemplo, não é transcendental; mas o conhecimento da origem ou da possibilidade de certas representações se referirem a priori aos objetos da experiência que é transcendental (SALGADO, 1995, p. 99, grifos do original).
\end{abstract}

A filosofia de Kant inaugurou uma metodologia crítica em relação ao conhecimento, estabelecendo que, mais importante que o objeto em si ou as condições para sua experiência, importa saber as condições de possibilidade para que o conhecimento ocorra. Em outros termos, antes de estudar as coisas, é preciso conhecer o modo de estudo dessas coisas e que estão presentes no sujeito, e não no objeto.

Todo o projeto da crítica kantiana e de sua filosofia transcendental modifica fundamentalmente a postura e a forma do problema da ciência. Conforme Trivisonno sintetiza, "o objeto não existe em si, sendo antes constituído pelo modo específico através do qual o sujeito conhece o material que lhe é dado ao conhecimento" (TRIVISONNO, 2021, p. XLIV). Mais detalhadamente, Siemek observa que

\begin{abstract}
No projeto da 'crítica' kantiana se modificam fundamentalmente a postura e a forma do problema filosófico da ciência. Esse problema deixa de ser um dos problemas filosóficos e torna-se o problema filosófico específico da filosofia como tal. Mas ele se torna um problema, por esse motivo, diferente do anterior, tratado pela 'teoria do conhecimento' pré-kantiana. Algo totalmente diferente é aqui a própria definição do 'conhecimento', como também o modo de tratar dele, em especial sua relação com o 'objeto'. Esta diferença é proveniente da nova perspectiva teórica na qual se põe todo o problema do conhecimento. (SIEMEK, 2003, p. 112).
\end{abstract}

Por sua vez, explica Losano: "O elemento central da ciência é, pois, o método e não o objeto; o cientista, portanto, visa à construção de uma teoria formal, não substancial" (LOSANO, in: KELSEN, 1998, p. XIII). Portanto, o Direito, a partir de Kelsen, deve ser entendido somente enquanto norma, elemento que decorre a legalidade específica do direito obtida por um projeto de caráter transcendental, com o qual o objeto é entendido, primeiramente, pela experiência, não se limitando nem se reduzindo, entretanto, a ela. É necessário, por conseguinte, identificar as condições de possibilidade para a ciência 
(conforme Kant estabeleceu na Crítica da Razão Pura), e que estão presentes, aprioristicamente, no sujeito.

Destarte, o fundamento filosófico da teoria pura de Kelsen, especialmente no contexto da primeira edição da obra homônima, encontra-se na filosofia kantiana ou, mais exatamente, na interpretação da teoria de Kant por Hermann Cohen, neokantiano da Escola de Marburgo, segundo o qual "não há objeto de conhecimento, a ser investigado segundo o método de uma determinada ciência, mas simplesmente o processo de conhecimento, que gera seu objeto" (LOSANO, in: KELSEN, 1996, p. XIV) ${ }^{6}$.

Assim, em relação à teoria pura do direito, a influência deste neokantismo ressalta-se no "modo específico como Kelsen concebe o conhecimento jurídico", o que, consequentemente, provocou muitas das críticas que Kelsen recebeu em sua obra, considerando-a como "formalismo jurídico", tanto no uso do neokantismo coheniano, quanto nas considerações sobre o direito como fenômeno estático. De fato, conforme argumenta Paulson,

em alguns momentos, Kelsen parece estar seguindo Kant, atribuindo à ciência do direito uma função "construtiva". Em outros momentos, ele parece se aliar a Hermann Cohen e aos outros da escola de Marburgo, introduzindo (...) o "fato" da ciência como o ponto de partida - no caso de Kelsen, o "fato" da ciência do direito. (PAULSON, in: OLIVEIRA; TRIVISONNO, 2013, p. 27).

Conforme escreve Kelsen, "a teoria pura do direito fortemente se opõe a toda tentativa que negue tanto o positivismo jurídico, quanto a filosofia transcendental kantiana" (KELSEN, 2021, p. 30). "A ciência do direito, enquanto conhecimento do direito, constitui ou seja, cria - o seu objeto" (TRIVISONNO, 2021, p. XLIV), que é a compreensão do direito enquanto norma. Para Kelsen, a possibilidade do conhecimento do direito enquanto uma ciência é a partir do ponto de vista normativo, que concebe o direito como conjunto de normas postas, factual e validamente existentes em um determinado contexto, alheias a qualquer valoração moral.

\footnotetext{
${ }^{6}$ Cf.: "Eppurre l'accusa di concepire formalmente anche la realtà giuridica venne un tempo rivolta a Kelsen, adducendo sia cò ch'egli aveva scritto nella sua prima opera importante, ove considera il diritto como fenomeno soltanto statico, sia fatto che egli si richiamava alle teorie epistemologiche della scuola neokantiana di Marburgo, nella formulazione di Hermann Cohen, secondo cui non esiste un oggetto di conoscenza, da indagara secondo ul metodo di una certa scienza, ma semplicemente il procedimento di conoscenza, che genera il suo oggetto" (LOSANO, in: KELSEN, 1966, p. XIII-XIV).
} 


\begin{abstract}
A teoria kelseniana do Direito depura assim os elementos jusnaturalistas tradicionais da dedução da validade e legitimidade de um ordenamento jurídico com base em conteúdos supostamente racionais, naturais, divinos, bem como a postura de centrarse em fatos normativos das teorias realistas, voltando-se a crítica de Kelsen para a perda da característica normativa do Direito (ALBUQUERQUE, in: BARRETO, 2006, p. 507).
\end{abstract}

Portanto, do mesmo modo que a filosofia transcendental de Kant se ergue contrária a toda metafísica, de cujo sono a filosofia de Hume despertou, Kelsen apresenta à ciência jurídica uma teoria pura, erigida contra as tratativas do direito natural. O capítulo III da obra desenvolve uma sequência de elementos que desembocarão na rejeição completa do direito natural com fins de assumir, integral e unicamente, o direito positivo.

\title{
2. A conceituação do Direito: Direito Natural x Direito Positivo
}

Kelsen realiza um percurso que passa pelo esclarecimento da definição de "teoria pura" a partir das noções clássicas de Direito Natural e Direito Positivo. Com efeito, Kelsen abre e fecha o capítulo III afirmando que a teoria pura deve ser compreendida como uma doutrina que combate o caráter ideológico da teoria tradicional na determinação do conceito de direito, que está sob influência do direito natural e que a teoria pura uma doutrina do Direito Positivo.

Como sabido, o Direito Natural é uma doutrina que opera com um conceito de direito transcendente, de caráter metafísico-filosófico. Mediante tal prisma, o direito é compreendido como um conjunto de princípios válidos para todos os tempos e lugares. Ademais, o Direito Natural considera que direito e justiça sejam vistos como intimamente correspondentes: direito é direito justo, validado pelo ideal de justiça. Por fim, o Direito Natural entende que todo direito torna-se objeto de uma valoração, cuja referência seria um sistema superior de normas ou princípios aos moldes de um direito ideal.

Conforme Bedin (in: BARRETO, 2006, p. 241), dentre muitas características do Direito Natural, destacam-se: a) a legislação em vigor deve ser analisada a partir de determinados conteúdos superiores, referentes, em suma, à ideia da justiça; b) esses conteúdos possuem como fonte uma determinada categoria universal e imutável (ideal de justiça); c) esses conteúdos devem sempre prevalecer sobre as disposições formais da legislação em vigor. Portanto, a legislação e todo o direito serão válidos e autorizados apenas em relação e 
na medida em que as prescrições jurisdicionais correspondam às exigências de um ideal de justiça.

Ora, Kelsen já expusera que é debalde qualquer tratativa que vise a uma concepção da justiça. Convém, na teoria pura, "libertar o direito daquelas relações que desde sempre foram feitas com a moral". Por ter um caráter metafísico nos limites de um dualismo ontológico (que pode levar a considerações tanto positivas, quanto negativas), considerações sobre a justiça ou valores não podem ser determinadas pela ciência e se torna "impossível responder à pergunta sobre em que consiste a justiça. Todas as tentativas nesse sentido até o momento levaram sempre a fórmulas completamente vazias" (KELSEN, 2021, p. 22-23).

Portanto, a teoria pura negará a perspectiva naturalista e ensejará esforços para combater qualquer tentativa em nome de uma abordagem transcendente do direito. Conforme a conclusão do capítulo, Kelsen afirmará que a "teoria pura do direito é a teoria do positivismo jurídico". Entende-se por ela, a princípio, a negação de qualquer tipo de especulação metafísica de alguma ordem superior ou finalidade transcendente com fins de explicar ou determinar os fenômenos. Partindo do positivismo sociológico comteano, consiste na aplicação de métodos ao Direito a fim de tentar obter o mesmo êxito presente em outras ciências. O método empírico é uma característica marcante (cf. GOMES, 1997, p. 106-107). O positivismo, portanto, não discute

\footnotetext{
a possibilidade da validade de uma ordem que está acima do direito positivo. Limitase ao direito positivo e evita que a ciência do direito faça o direito ser considerado uma ordem mais elevada. Evita que a discrepância entre um ideal de justiça de algum modo pressuposto e o direito positivo seja mal-usada contra a validade do direito positivo (KELSEN, 2021, p. 41).
}

Kelsen deixa evidente que o conceito de Direito que a Teoria Pura desenvolve é do direito positivo, isolado de "formas de ideologia jusnaturalistas da justiça". Neste particular, ressalte-se que o conceito de direito no viés positivo é contrário a qualquer tipo de especulação metafísica: não há nenhuma ordem superior ou finalidade transcendente para explicar ou determinar os fenômenos jurídicos. E, com tal, o conceito de direito fortalece-se em uma tendência anti-ideológica (KELSEN, 2021, p. 41).

Kelsen impõe autonomizar a ciência do direito, metodologicamente, como ciência das normas, face à sociologia e à psicologia jurídica. A abordagem conjunto destas ciências com o Direito, embora pertencentes a certo modo positivo de abordagem do direito, não 
consideram integralmente a ciência do direito como ciência autônoma, mas tão somente como técnica jurisprudencial ligada à sociologia do direito ${ }^{7}$.

Nesse aspecto, Kelsen reconhece que, embora tenha havido uma passagem radical do direito natural ao positivismo, especialmente por causa de transformações no século XIX, a passagem foi insuficiente: há, ainda, influência do direito natural no conceito de direito, uma vez que ele é compreendido mediante um viés de valor absoluto. Uma crítica se dirige aos pensadores que, embora distingam justiça e direito em seu pensamento, mantêm-se reféns da conexão moral justiça-direito. Para a teoria pura, é necessário que o princípio positivista chegue às últimas consequências, afastando-se, em definitivo, de qualquer abordagem que ainda entenda que o "direito positivo precisa corresponder a um mínimo ético, participando do ideal da justiça” (KELSEN, 2021, p. 27) e apresentando-se como um positivismo crítico.

Todo o pensamento jurídico-positivo, quer disso tenha consciência, quer não, parte
de uma norma que considera como válida. E é esta consciência dos próprios
pressupostos que a "Teoria Pura do Direito" vem trazer ao positivismo jurídico. Por
isso é que o positivismo kelseniano nos é também apresentado como um
"positivismo crítico" (...) Com a "Teoria Pura do Direito" continuamos, pois, no
terreno do positivismo jurídico. Só que este positivismo - a que se tem chamado
lógico -, sendo um positivismo autoconsciente, consciente de seus próprios
fundamentos e limites, não nega a legitimidade do problema axiológico, mas limita-
se a verificar a impossibilidade do seu tratamento científico (MACHADO, Nota
Preambular, In: KELSEN, 2001, p. 8;11).

Com efeito, o positivismo jurídico assume uma atitude que considera o direito, enquanto verdadeira ciência, como fato, não como valor e, por conseguinte, estuda o direito tal qual é, não tal qual deveria ser (cf. KELSEN, 2021, p. 24). Direito, aqui, entende-se como "aquele que efetivamente se manifesta na realidade histórico-social". Nas palavras de Kelsen (2021, p. 26), deve-se reconhecer o direito como integralmente (e não apenas predominantemente) orientado pelo positivismo e admitir o direito como mutável e condicionado por circunstâncias espaciotemporais, não mais pressuposto como uma categoria eterna e absoluta. $\mathrm{O}$ direito vale somente enquanto direito positivo, independe de sua validade moral: "a justificação do direito positivo não é realizada atualmente com base em (esse) outro direito superior, mas antes com base no próprio conceito de direito" (KELSEN, 2021, p. 42; $61)$.

\footnotetext{
${ }^{7}$ Segundo Kelsen, a ciência jurídica deve se ocupar do seu objeto de estudo: a norma positivada. Pesquisar as fontes primárias ou fundacionais do direito não é papel do cientista do direito, mas pode ser do sociólogo (LOSANO, in: KELSEN, 1998, p. XVI).
} 
"A ciência do direito só pode ser pura porque ela se dedica ao direito somente enquanto norma, nada além disso", e "ocupa-se não com o direito como ele deve ser, mas antes com direito como ele é”, conforme expressa Trivisonno (2021, p. XLV-XLVI). Eis que a pureza não é outra coisa senão a integral compreensão do Direito Positivo, tendo como ponto de vista o procedimento puramente normativo. Tal ponto de vista concebe metodológica e efetivamente o direito enquanto um conjunto de normas postas, sem se preocupar com valorações morais ou baseadas em algum conceito abrangente de justiça.

O positivismo jurídico possui uma estreita ligação com o processo de codificação do Direito, ou seja, pressupõe a centralidade na lei enquanto objeto da ciência do Direito. Kelsen vê o Direito como ordenamento normativo, enquanto norma, e esta é trabalhada cuidadosamente no Capítulo III. A teoria pura, enquanto ciência jurídica, deve se ocupar do seu objeto de estudo: a norma positivada, a partir da categoria do dever ser.

\section{A Doutrina da Proposição Jurídica e o Dever Ser}

Um segundo ponto importante trabalhado no capítulo desenvolve-se em torno da compreensão de norma. De fato, em Kelsen, as normas exprimem um dever e uma sanção correspondente. A norma jurídica exprime um dever, um dever ser, que motiva, ainda que não unicamente, as condutas humanas. A compreensão de norma leva ao esclarecimento da noção de dever ser, bem como à acepção do direito como técnica social específica mediante uma coação.

Com próprio de sua metodologia, Kelsen rechaça a compreensão "transcendente" do dever ser. Essa posição espiritual compreende o direito ainda nas linhas do valor absoluto, próprio da moral: não coloca em dúvida um valor absoluto da moral (não negado, tampouco abordado pela jurisprudência). Por conseguinte, o conceito de Direito presumiria um elemento ideológico, cujo livramento será tarefa da teoria pura do direito. Como já visto, a teoria pura separa completamente o conceito de norma jurídica do conceito de norma moral, assegurando autonomia e legalidade própria do direito em si e em relação à lei ética.

Para tanto, faz-se necessário entender que a norma jurídica não deve ser compreendida como um imperativo, mas como um juízo hipotético que expressa a conexão 
entre um pressuposto fático condicionante ${ }^{8}$ e uma consequência condicionada, mediante uma imputação. Não é apenas um dever, como seria possível nas normas morais ou religiosas. A norma jurídica apresenta a conexão entre uma sanção e um ato. Como juízo hipotético, “contém a 'vontade' do estado - e que determina que um pressuposto fático-jurídico (Tatbestand) deve ser seguido de uma desvantagem (...) a norma jurídica autêntica é aquela que liga um ato de coação a determinado pressuposto” (TRIVISONNO, 2020, p. 75).

Eis a peculiaridade do direito: ele é, segundo a teoria pura, formado por comandos sancionados. Voltando à distinção com outros tipos de normas, especialmente às normas éticas, a norma jurídica vincula uma sanção a determinado comportamento: atribui-se, portanto, à conduta contrária à prescrita um ato de coação organizado objetivamente. Nisso se fundamenta o conceito do direito e de todo ordenamento jurídico.

Na sequência, Kelsen identifica a norma jurídica com a proposição jurídica. Segundo o jurista, "a norma jurídica torna-se proposição jurídica, que expressa a forma fundamental da lei” (KELSEN, 2021, p. 28). A proposição jurídica seria uma espécie de reformulação, por parte da ciência do direito, das normas jurídicas ou, mais precisamente, uma nova apresentação do material jurídico-positivo para se chegar à verdadeira norma jurídica.

Ainda conforme Trivisonno, (2020, p. 81), a "proposição jurídica" enuncia o conteúdo do direito, a saber, que mediante a prática de determinada conduta deve ocorrer um ato coativo como consequência. Com efeito, Kelsen expressa que a norma/proposição jurídica "conecta a condição jurídica com a consequência jurídica" (consequência do ilícito), e a imputação (relação entre ato e sanção, entre pena e delito) é a legalidade específica do direito, uma vez que possui um sentido normativo. A consequência jurídica/do ilícito é reconduzida a sua condição jurídica, mediante o princípio de imputação (relação de condição e consequência) (cf. KELSEN, 2021, p. 28).

A imputação, bem como a existência específica do direito (validade) é, para Kelsen, o dever ser. É ela que faz a lei jurídica expressar-se enquanto: "Se A é, então B deve ser". E nessa relação, não há nenhuma atribuição moral ou política. Para Kelsen, a teoria pura do

\footnotetext{
${ }^{8}$ Atente-se que não é um mero fato, mas um fato que aparece em uma norma jurídica como condição (pressuposto) e ao qual é ligado uma sanção como consequência (Cf. TRIVISONNO, Notas sobre a Tradução. In: KELSEN, 2021, p. XIX).
} 
direito representa o direito positivo por meio do "dever ser", cujo sentido, é, cognitiva e teoricamente, transcendental, (no sentido a $_{\text {priori }}{ }^{9}$ da filosofia kantiana).

O dever ser é uma categoria relativamente apriorística, indispensável forma pela qual o direito positivo conecta os fatos (...) Quando se firma que se algum ilícito ocorre "deve" ocorrer sua consequência, esse "dever ser" significa o sentido específico pelo qual a condição jurídica e a consequência do ilícito estão associadas na proposição jurídica. Essa categoria do direito tem um caráter puramente formal, o que a distingue fundamentalmente de uma ideia transcendente do direito (KELSEN, 2021, p. 30).

Entretanto, Kelsen não deixa de apontar que o sentido normativo do dever ser é frequentemente negado. Com isso, há uma visão reduzida da ordem jurídica, fazendo com que a proposição jurídica/norma jurídica seja dissolvida como um empreendimento a produzir nos seres humanos representações motivadoras de/para o comportamento adequado. Termos outros, reduz-se o direito a meio para "gerar determinado comportamento padrão dos seres humanos", ignorando conscientemente o sentido normativo específico e diferente do senso moral que ocorre nos atos. O conceito de Direito que a proposição jurídica define é norma ou o dever ser liberado de qualquer valor moral absoluto (ideologia). Os atos jurídicos devem ser considerados somente como evento natural em que ocorre o nexo causal, em sua facticidade.

Trabalhando nessa perspectiva, Kelsen determina, em relação à ciência do direito e à categoria do dever ser ou da norma, a necessidade de limitar o objeto e esclarecer o método específico. Se sempre "haverá uma doutrina normativa do direito enquanto houver um direito" (KELSEN, 2021, p. 40), essa doutrina precisa estabelecer a finalidade, objeto e metodologia da ordem jurídica. E Kelsen centraliza sua concepção de direito como a norma que determina uma coação.

\section{Norma Coativa e Estrutura da Proposição Jurídica}

A teoria pura continua a tradição do positivismo do século XIX, que considera que norma jurídica é uma norma coativa, norma que determina a coação. Com efeito, Kelsen reafirma que, na norma/proposição jurídica, a consequência que é conectada a uma determinada condição é o ato de coação estatal. Pela coação, qualifica-se o pressuposto fático condicionante como ilícito e o condicionado é qualificado como consequência do ilícito.

\footnotetext{
${ }^{9}$ Em outros termos, o sentido do dever-ser é aplicável independentemente do conteúdo dos fatos conectados e, por isso, permanece preservado contra toda ideologia.
}

Teorias do Direito e Realismo Jurídico | e-ISSN: 2525-9601| Encontro Virtual | v. 7 | n. 1 | 
O que torna determinado comportamento humano contrário ao direito é única e exclusivamente o fato de esse comportamento ser estabelecido na proposição jurídica como condição de uma consequência específica, ou seja, o fato de a ordem jurídica positiva reagir a esse comportamento com um ato de coação (KELSEN, 2021, p. 31)

Especificamente, a norma jurídica implica tanto uma condição, quanto uma consequência, vinculadas por uma imputação. A consequência jurídica consiste exatamente em um ato coativo. Para Kelsen, a categoria formal do dever ser ou da norma determina-se justamente pela caracterização da norma, por conseguinte, do direito, como norma de coação. Segundo Sgarbi (In: BARRETO, 2006, p. 808), “o direito é uma técnica de motivação indireta das condutas humanas", uma vez que o comportamento pode se obter pelo uso de sanções punitivas organizadas socialmente. Na proposição jurídica, um comportamento é estabelecido como condição de uma consequência: o dever jurídico define-se, portanto, com base em um ato coativo ligado pela proposição jurídica a um fato.

O direito é norma coativa: isso que o diferencia, especificamente, da moral ou de qualquer outra ciência social. Ao considerar o direito como norma coativa, Kelsen estabelece os fundamentos do que será sua teoria da estrutura das normas jurídicas. O ponto de partida para essa teoria é a reinterpretação do conceito de ilicitude, para o qual importa, tão somente "o fato de o pressuposto fático se encontrar na proposição jurídica: que ele seja condição da reação específica do direito, do ato de coação" (KELSEN, 2021, p. 32).

Com efeito, diferentemente das perspectivas jusnaturalistas, Kelsen afirma que o ilícito não é quebra ou violação do Direito. $\mathrm{O}$ ato ilícito ou antijurídico não é um ato contra o direito. Antes, o contrário: é um pressuposto, a condição específica do direito e pelo qual o direito cumpre seu papel com o uso de uma coação. "Com o ilícito prova-se a existência do direito", que consiste em sua validade ou no dever ser do ato de coação como consequência do ilícito (KELSEN, 2021, p. 33). Conforme a síntese de Trivisonno:

"Kelsen entende que, diante da conceituação da norma jurídica como a norma que liga um ato coativo o conceito de antijuridicidade não pode continuar sendo definido como negação do direito, o que revelaria uma postura política. A antijuridicidade passa a ser compreendida como uma conduta determinada na proposição jurídica como condição do ato coativo nela estabelecido como consequência". (TRIVISONNO, 2021, p. 82). 
Pela norma coativa, chega-se à finalidade da ordem jurídica, a saber, incitar os seres humanos, através da representação da ameaça (ato de coação), à prática de uma conduta oposta que evite tal coação. Conforme expressa Kelsen, "a eficácia pretendida pela ordem jurídica baseia-se nessa motivação" ao comportamento humano, uma vez que somente o ser humano é incitado a praticar um comportamento em conformidade com a norma (mediante a representação de uma norma em sua razão e vontade). De um ponto de vista puramente positivista, o direito é concebido como uma ordem exterior de coação, além de ser uma técnica social específica. De fato, "através da ligação, a ele, de um ato de coação" o estado social desejado realiza-se.

Parte fundamental da doutrina da proposição jurídica é sua estrutura, apresentada na distinção entre Norma Primária e Norma Secundária. Ora, uma vez claro que cada pessoa precisa comportar-se de modo a evitar um ato de coação, Kelsen expressa que se pode decompor a ordem jurídica em uma "soma de normas em que o comportamento pretendido pelo direito aparece como proibido", como, por exemplo, "não se deve matar", "os contratos devem ser cumpridos”. Mas, nessas proposições, a conexão com o ato de coação não é expressada e, consequentemente, o direito ficaria sem sua especificidade.

Portanto, Kelsen afirmará que o que se pretende com a ordem jurídica e que é estatuído em uma norma que evita a sanção, constitui-se como uma norma jurídica somente quando expressa, também, uma sanção. É necessário expressar-se completamente, isto é, "que sob a condição da conduta oposta um ato de coação deve ocorrer como consequência". A expressão do ato de coação na proposição jurídica é a norma jurídica em sua forma primária, ao passo que "a norma que estatui a conduta que evita a sanção pode ser considerada norma secundária” (KELSEN, 2021, p. 35).

A norma primária é, portanto, o comportamento condicionante do ato de coação. Ela evidencia o dever e é constituída pela proposição jurídica, quando esta liga um pressuposto a uma coação ("Se A, deve ser B"). De fato, a norma jurídica deve enfatizar o caráter coativo do Direito, cuja ideia de dever parece evidenciar-se ante a possibilidade de uma sanção. Por sua vez, a norma secundária é a representação do comportamento (pressuposto fático devido), que evita o ato de coação. Evidencia a conduta que evita a coação e, por isso, acaba sendo supérflua, costumeira. Em síntese:

(...) o ordenamento jurídico pode ser, para Kelsen, "resumido" como conjunto de normas dirigidas a essas condutas que evitam o ato coativo, normas como "não se 
deve matar", "deve-se pagar um empréstimo" etc. Porém, afirma Kelsen, quando se considera as normas secundárias, uma característica essencial do direito fica sem expressão: sua relação essencial com o ato coativo fático. $\mathrm{Na}$ visão de Kelsen, a norma jurídica secundária pode até ser adotada para fins de simplificação e comodidade, para expressar que não se deve praticar a conduta que leva à sanção. Contudo, como já mencionado, somente a "proposição jurídica" conseguiria enunciar de forma integral e correta o conteúdo do direito: mediante a prática de determinada conduta deve ocorrer um ato coativo como consequência (TRIVISONNO, 2020, p. 82).

Seria o comportamento humano conforme a ordem jurídica apenas efeito da representação provocado pela ameaça do ato de coação? Não: a correspondência entre o comportamento real dos seres humanos e a ordem jurídica não precisa necessariamente ser atribuída à eficácia da ordem jurídica, mas também a ideologias, cuja função é levar a essa correspondência ou promovê-la.

Em Kelsen, o direito assume um modo específico, caracterizado de tal modo que mostre por que a norma jurídica secundária formulada não possa constituir sozinha, sem referência à proposição jurídica que conecta a condição jurídica à consequência jurídica, a expressão essencial do direito. O direito é um aparato de coação, que não possui qualquer valor político ou ético em si e por si. O conceito de dever jurídico é determinado com base na norma primária que, conforme Trivisonno (2020, p. 77), é, em Kelsen, conceituada como norma primária.

\section{Considerações Finais}

O capítulo III da Teoria Pura do Direito (primeira edição) apresenta temas fundamentais de toda a teoria e que serão mais desenvolvidos ao longo dos demais capítulos. Os conceitos são pensados dentro da proposta metodológica estabelecida pela filosofia transcendental kantiana, bem como pelo positivismo jurídico. A teoria pura combate o caráter ideológico da teoria tradicional do direito, fundamentada em perspectivas jusnaturalistas, e se estabelece na determinação positivista do conceito de direito.

De fato, com a perspectiva transcendental e positivista, Kelsen conceitua o que é o objeto e como deve ser desenvolvido o estudo do direito enquanto uma ciência. O direito deve ser estudado fora das abordagens que se questionam como deveria ser, mas sobre o que é e como é o direito. E o conhecimento do direito estabelece o objeto e a ciência do direito, ao se dirigir a normas que conferem a fatos específicos o caráter de atos jurídicos. Radicaliza, 
assim, a passagem já iniciada doutrinalmente que separa o conceito de norma jurídica do conceito de norma moral, assegurando autonomia e legalidade própria ao direito em relação à lei ética pela centralidade da norma.

Na Teoria Pura do Direito, Kelsen, ao adotar o método kantiano que considera o sujeito como constituidor do objeto, fortalece sua abordagem normativa do Direito. A Ciência do Direito deve ser enfrentada pelo ponto de vista normativo, alcançado pelo cientista em suas abordagens. O Direito é conhecido como norma, reconstruída enquanto proposição jurídica, sentido de um ato de vontade por meio de um dever-ser. A proposição jurídica evidencia a ligação do ato de coação com um pressuposto, enfatizando, portanto, o caráter coativo do direito.

Ora, como visto, Kelsen considera que a norma jurídica é uma norma coativa, norma que determina a coação. A norma jurídica torna-se proposição jurídica, que expressa a forma fundamental da lei, pois enuncia o conteúdo do direito: mediante a prática de determinada conduta, deve ocorrer um ato coativo como consequência. O conceito de Direito que a proposição jurídica define é norma ou o dever ser liberado de qualquer valor moral absoluto (ideologia). Os atos jurídicos devem ser considerados somente como evento natural em que ocorre o nexo causal, em sua facticidade, não nos moldes de "ter de ser", mas do "dever ser".

Quando se firma que se algum ilícito ocorre "deve" ocorrer sua consequência, esse “dever ser” significa o sentido específico pelo qual a condição jurídica e a consequência do ilícito estão associadas na proposição jurídica. A imputação, bem como a existência específica do direito (validade) é, para Kelsen, o dever ser.

A norma jurídica deve enfatizar o caráter coativo do Direito. Por isso, Kelsen, em uma teoria da estrutura da proposição jurídica, distingue, na proposição, normas primárias e normas secundárias. O dever é evidenciado pela proposição jurídica e esta é a norma primária, pois liga um pressuposto a uma coação. É a verdadeira proposição jurídica, portanto. Como secundária, Kelsen considera a representação do comportamento (pressuposto fático devido), que evita o ato de coação, invertendo, destarte, a concepção clássica sobre a norma jurídica.

\section{Referências}

BARRETO, Vicente de Paulo (Coord.). Dicionário de Filosofia do Direito. São Leopoldo/Rio de Janeiro: Unisinos/Renovar, 2006. 
CONSANI, Cristina Foroni. Kelsen leitor de Kant: considerações a respeito da relação entre direito e moral e seus reflexos na política. Princípios: Revista de Filosofia (UFRN), v. 23, n. 41, p. $125-170,28$ set. 2016.

GOMES, Alexandre Travessoni. A Norma Fundamental em Kelsen. Revista do CAAP, Belo Horizonte, n. 2, p. 103-124, 1997. Disponível em https://revistadocaap.direito.ufmg.br/index.php/revista/article/view/212/211. Acesso em 3 abr. 2021.

KANT, Immanuel. Crítica da Razão Pura. Trad. Manuela Pinto dos Santos e Alexandre Fradique Morujão. 2.ed. Lisboa: Fundação Calouste Gulbenkian, 1989.

KELSEN, Hans. A Justiça e o Direito Natural. Trad. e Prefácio João Baptista Machado. Coimbra: Almedina, 2001. (Coleção Studium).

KELSEN, Hans. O problema da justiça. Trad. João Baptista Machado. 3.ed. São Paulo: Martins Fontes, 1998.

KELSEN, Hans. Teoria Pura do Direito: Introdução à Problemática Jurídico-Científica. Primeira Edição Alemã. Tradução e ensaio introdutório: Alexandre Travessoni Gomes Trivisonno. Rio de Janeiro: Forense Universitária, 2021.

LOSANO, Mario G. Saggio Introdutivo. In: KELSEN, Hans. La Dottrina Pura del Diritto. Trad. Mario Losano. Torino: Einaudi, 1966, XII-LVII

OLIVEIRA, Júlio Aguiar de; TRIVISONNO, Alexandre Travessoni Gomes. (Org.) Hans Kelsen: teoria jurídica e política. Rio de Janeiro: Forense, 2013.

PAULSON, Stanley L. Toward a Periodization of the Pure Theory of Law. In: GIANFORMAGgIO, Letizia (org.). Hans Kelsen's Legal Theory: a diachronic point of view. Turin: G. Giappichelli Editore, 1990, p. 11-47.

PAULSON, Stanley L. Four Phases in Kelsen's Pure Theory of Law? in: Oxford Journal of Legal Studies, n 18, v. 1, p. 153-166, 1998. Disponível em https://www.jstor.org/stable/764726?seq=1. Acesso em 10 abr. 2021.

SALGADO, Joaquim Carlos. A Ideia de Justiça em Kant: seu fundamento na liberdade e na igualdade. Belo Horizonte: Editora UFMG, 1995.

SIEMEK, Marek J. A concepção da Filosofia Transcendental. Síntese, Belo Horizonte, v. 30 n. $96, \quad$ p. 107-118, 2003. Disponível em https://faje.edu.br/periodicos/index.php/Sintese/article/view/510/933. Acesso em 2 abr. 2021.

TRIVISONNO, Alexandre Travessoni Gomes. A Teoria da Estrutura Hipotética das Normas Jurídicas de Kelsen: características, evolução e balanço de sua importância. Revista Brasileira de Estudos Políticos, Belo Horizonte, n. 12, pp. 73-120, jul./dez. 2020. 
TRIVISONNO, Alexandre Travessoni Gomes. Estudo Introdutório: o lugar e alguns dos principais temas da primeira edição da Teoria Pura do Direito no contexto geral da obra de Kelsen. in: KELSEN, Hans. Teoria Pura do Direito: Introdução à Problemática JurídicoCientífica. Primeira Edição Alemã. Tradução e ensaio introdutório: Alexandre Travessoni Gomes Trivisonno. Rio de Janeiro: Forense Universitária, 2021. 